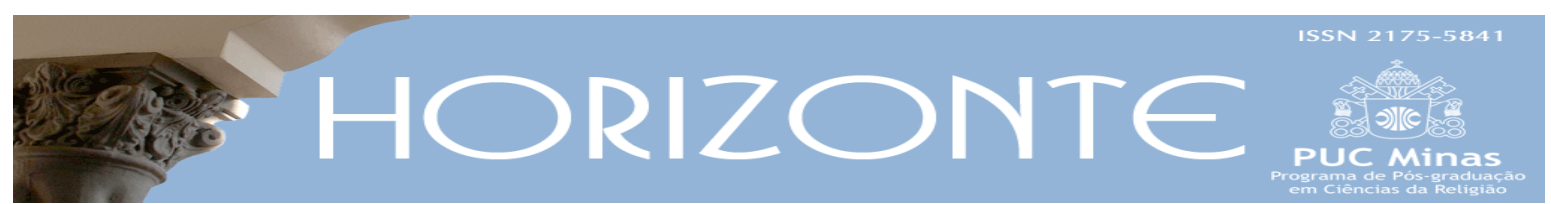

Dossiê: Religião e Educação - Artigo original ๑。

DOI - 10.5752/P.2175-5841.2020v18n55p223

\title{
A leitura do sagrado: uma metodologia ativa na Cultura Religiosa
}

\author{
The reading of the sacred: \\ an active methodology within the subject of "Cultura Religiosa"
}

Edile Fracaro Rodrigues*

\begin{abstract}
Resumo
A presente pesquisa documental, numa abordagem qualitativa, buscou penetrar em um ambiente cultural e religioso, a partir de documentos produzidos por estudantes universitários. No "Clique do Sagrado", atividade pedagógica desenvolvida por estudantes da PUCPR, o Sagrado se tornou fonte de leitura. Imagens, símbolos, gestos e espaços são os elementos que constituem essa leitura. A atividade se constitui de foto e texto sobre o sagrado e tem por objetivo sensibilizar o estudante de Cultura Religiosa da PUCPR em relação ao Sagrado e a sua espacialidade e dimensão cultural. A pesquisa documental, numa abordagem qualitativa tem como base dois recortes temporais: primeiro semestre de 2015 e primeiro semestre de 2018. Em 2015, os dados levantados foram construídos a partir da análise de um blog e os dados de 2018 têm procedência de um processo interno da instituição de ensino. Procurou-se trazer o estudante como protagonista desse processo, sensibilizando-o em relação ao Sagrado e sua espacialidade e dimensão cultural. Trata-se, assim, de educar para o "saber olhar" o ser humano em sua diversidade de manifestações. A proposta do "Clique do Sagrado" procura colaborar para a sistematização do conhecimento apresentado em sala de aula, para uma leitura social das manifestações religiosas, integrando o cotidiano e as tecnologias educacionais da ação docente.
\end{abstract}

Palavras-chave: Sagrado. Diversidade Cultural e Religiosa. Metodologias Ativas.

\begin{abstract}
This documentary research, in a qualitative approach, sought to penetrate a cultural and religious environment, from documents produced by university students. In the "Clique do Sagrado", pedagogical activity developed by PUCPR students, the Sacred became a source of reading. We intend to bring the student as protagonist of this process, sensitizing him in relation to the Sacred and its spatiality and cultural dimension. Images, symbols, gestures and spaces are the elements that constitute this reading. The activity consists of a photo and text about the sacred and aims to sensitize the student of Religious Culture da PUCPR in relation to the Sacred and its spatiality and cultural dimension. This documentary research, in a qualitative approach, is based on two time cuts: first half of 2015 and the first half of 2018. In 2015 the data collected was constructed from the analysis of a blog and the 2018 data are from an internal process of the educational institution. Thus, it is about educating for the "knowing how to look" the human being in its diversity of manifestations. The proposal of the "Clique do Sagrado" seeks to contribute to the systematization of knowledge by presenting in the classroom for a social reading of religious manifestations integrating daily life and educational technologies of teaching action.
\end{abstract}

Keywords: Sacred. Cultural and Religious Diversity. Active Methodologies.

Artigo submetido em 12 de novembro de 2019 e aprovado em 25 de abril de 2020.

*Doutora em Teologia pela PUCPR. Professora da PUCPR. País de origem: Brasil. E-mail: edilefracaro@gmail.com 


\section{Introdução}

Num mundo em constante transformação e com tantas informações disponíveis, há que se refletir sobre o processo educacional. A resolução de situações autênticas, que envolvam diferentes graus de complexidade, tem sido contemplada pelas metodologias ativas como uma proposta para o desenvolvimento do protagonismo do/a estudante. Espera-se a leitura e interpretação da realidade e, a partir dessa interpretação, a articulação de diferentes saberes, a promoção do respeito e do direito à liberdade de expressão e de consciência e a participação do cidadão na sociedade de forma autônoma.

E esse é um grande desafio: ler bem o mundo em que se está imerso, escolhendo e tratando informações, transformando-as em conhecimento pertinente, ou seja, aquele "capaz de situar qualquer informação em seu contexto" (MORIN, 2000a, p. 15). Mais do que acumular conhecimentos, o importante é estar apto para viver num mundo em permanente e acelerada mudança. Para Morin (2008, 35), “[...] aprender a viver é o propósito da educação e essa aprendizagem é transformar informação em conhecimento, o conhecimento em sabedoria e incorporar a sabedoria à vida”.

As reflexões de Morin trazem inquietações para a educação e a formação docente que se potencializam pelas constantes mudanças tecnológicas. Nas palavras de Morin, precisamos ir além da compreensão intelectual desse humano, pois "compreender inclui, necessariamente, um processo de empatia, de identificação e de projeção. Sempre intersubjetiva, a compreensão pede abertura, simpatia e generosidade." (MORIN, 2000, p.94-95).

Como isso reflete sobre a religião no espaço escolar? A presente pesquisa documental, numa abordagem qualitativa, buscou penetrar em um ambiente cultural e religioso, a partir de documentos produzidos por estudantes universitários da Pontifícia Universidade Católica do Paraná (PUCPR), tendo como questões norteadoras a relação de uma leitura do religioso no cotidiano e a abertura para a diversidade cultural e religiosa. 
A atividade consistia em fotografar, utilizando celular ou câmera fotográfica, uma cena do cotidiano ou espaço que remetesse a uma expressão do Sagrado. Além da imagem era necessário inserir um comentário sobre o que a cena representava, qual a motivação para a foto e estabelecer relação com os textos abordados em sala de aula. O objetivo da atividade era sensibilizar o/a estudante de Cultura Religiosa da PUCPR em relação ao Sagrado e a sua espacialidade e dimensão cultural.

A pesquisa teve como base dois recortes temporais: primeiro semestre de 2015 e primeiro semestre de 2018. Os dados de 2015 foram construídos a partir da análise de "Cliques do Sagrado" (foto e texto) de 15 estudantes de diversos cursos de graduação (Ciências Contábeis (2 turmas), Administração (3 turmas), Marketing, Design Digital, Engenharia Civil (2 turmas), Engenharia de Computação, Engenharia Química, Engenharia de Produção, Medicina Veterinária e Psicologia).

O "clique" deveria ser inserido no blog próprio da instituição e uma equipe de professores da disciplina escolheu um "clique" de cada turma. Em seguida foi criado um blog "Um Clique do Sagrado" fora do ambiente virtual da instituição. Os estudantes receberam o link desse blog para votar no melhor "clique". Foram 1766 visualizações e mais de mil votos computados em uma semana. A pesquisa documental se deu a partir do "clique desse blog externo.

O mesmo processo do blog da instituição (blog interno) foi aplicado em 2018, com 27 estudantes do curso de Letras, agora contando com o uso de metodologias ativas. $\mathrm{O}$ depoimento dos/das estudantes têm procedência de um processo interno da instituição de ensino para avaliação docente. Em 2018, foram introduzidas metodologias ativas como storytelling, avaliação por pares e autoavaliação. A essência do "Clique do Sagrado" que era a foto permaneceu.

Importante destacar que em ambos os casos foi preservada a identidade dos estudantes e a pesquisa documental foi orientada pelos mesmos indicadores de pesquisa, como se verá a seguir. 
Para Figueiredo (2007), os documentos são utilizados como fontes de informações, indicações e esclarecimentos que trazem seu conteúdo para elucidar determinadas questões e servir de prova para outras, de acordo com o interesse do pesquisador(a).

A análise apresentada faz parte de um processo de pesquisa que se iniciou em 2006, com uma pesquisa a partir de frases e desenhos elaborados por professores e professoras do Ensino Fundamental da Rede Estadual de Ensino do Paraná acerca da concepção do Ensino Religioso (RODRIGUES, 2008). À época, percebeu-se que ao apresentar a diversidade cultural religiosa, "favorecia-se o desenvolvimento de uma liberdade da identidade pessoal" (RODRIGUES, 2008, p.109). O que levou à uma segunda pesquisa, a percepção de professores e professoras do Ensino Médio de uma rede de ensino privado sobre a diversidade cultural e religiosa em sala de aula (RODRIGUES, 2018). Essas pesquisas procuraram discutir o ER, seus fundamentos históricos e pedagógicos para a devida formação docente. A presente análise tem como foco o olhar do estudante sobre o Sagrado e sua relação no cotidiano. É uma prática docente aplicada a estudantes universitários, da disciplina de Cultura Religiosa da PUCPR, mas que poderia ser aplicada na Educação Básica brasileira.

\section{0 contexto da disciplina}

Na PUCPR, a disciplina de Cultura Religiosa é integrante do Eixo de Formação Humana, juntamente com Filosofia, Ética e Projeto Comunitário. O Eixo humanístico contribui para a formação integral dos estudantes porque estabelece relações entre o humano, o social, o tecnológico, o biológico e o transcendente. Os estudantes têm oportunidade de refletir a respeito de temas ligados às humanidades e a religiosidade é um desses temas.

O ambiente universitário é um ambiente rico em diversidade e pode proporcionar aos estudantes um espaço de interação e convivência entre pessoas de diferentes origens, costumes e crenças religiosas fazendo com que cada um possa ampliar suas visões de mundo, partilhando democraticamente o mesmo espaço. 
A identidade da disciplina de Cultura Religiosa da PUCPR vincula-se à perspectiva de uma formação humana, discutindo a diversidade cultural para reler a dinâmica sociorreligiosa. E o desafio no Ensino Superior é encaminhar metodologicamente esse processo para promover simultaneamente a mediação entre a sociedade e a universidade, a cultura e as aprendizagens socialmente significativas, e a teoria e a prática.

Para Santos Neto (PUC Minas), o professor de Cultura Religiosa se depara com muitos desafios e um deles é "a sensibilização da comunidade acadêmica para a relevância da disciplina no curriculum regular de cada curso, tarefa que deve acompanhar o professor desde o primeiro até o último dia de aula." (SANTOS NETO, 2004, 145). E ainda afirma que "a importância da disciplina será afirmada e confirmada através de sua inserção no contexto e dinâmica pedagógica de cada curso, à medida que se fizer presente nas atividades interdisciplinares”.

Klering (2011, p. 130), ao falar da disciplina de Cultura Religiosa, na PUCRS, aponta para um contexto de educação integral e como "uma possibilidade transdisciplinar latente ainda pouco explorada, mas que a vocaciona para ser sempre mais um espaço integralizador da educação”. O autor ainda aponta a importância desta disciplina, "por sua origem interdisciplinar, por se desenvolver no âmbito da cultura e da religião e se concretizar no espaço acadêmico da educação".

Como uma das atividades em que o ser humano pode se conhecer, construir e interpretar suas experiências, a religiosidade é um tipo de conhecimento humano, "que responde as questões existenciais do ser humano e reflete sobre a sua dimensão religiosa. É o mesmo ser humano que pensa, sente e vive a experiência religiosa” (JUNQUEIRA et al, 2017, p. 21).

O desafio é o engajamento dos estudantes e a devida contextualização da disciplina para a sua formação pessoal e profissional. A prática em questão, "Clique do Sagrado”, foi idealizada, a princípio para o espaço universitário e em seu escopo contempla o uso de metodologias ativas (foto e texto, storytelling, Avaliação por 
Pares e Autoavaliação). Para abordar o conhecimento religioso e a formação de um espaço democrático de convivência entre as culturas e religiões, procurou-se trazer o estudante como protagonista desse processo, sensibilizando-o em relação ao Sagrado e sua espacialidade e dimensão cultural.

Desde 2015, a formação continuada oferecida pela PUCPR aos docentes tem especialmente abordado as metodologias ativas, entendidas como diferentes maneiras de desenvolver o processo do aprender "com a intenção da formação crítica de futuros profissionais, em várias áreas do saber" (CAMAS; BRITO, 2017, p. 314). A aplicação de tais metodologias, segundo Camas e Brito, além de favorecer a autonomia do estudante, desperta a curiosidade e estimula tomadas de decisões individuais e coletivas, advindas das atividades essenciais da prática social e nos contextos do estudante.

\section{Sagrado: fonte de leitura}

Para Rodrigues (2017, p. 207), o cotidiano "está permeado de situações que envolvem desafios cognitivos, sociais e emocionais. Frente a esses desafios, são mobilizados saberes que decorrem da aprendizagem, um processo significativo e complexo que envolve o indivíduo na sua totalidade”.

O "Clique do Sagrado"1 é uma atividade desenvolvida desde 2015 e que já conta com mais de 4000 estudantes participantes. Com a análise dos documentos produzidos pelos estudantes em 2015 e 2018, buscou-se penetrar em um ambiente cultural e religioso. A perspectiva de uma leitura religiosa no espaço acadêmico é compatível com a postura de um país que respeita a liberdade religiosa de sua população e resguarda, assim, o direito de não comprometimento com nenhuma tradição religiosa. Essa orientação se apresenta na revisão do artigo 33, aprovada em 1997, da Lei de Diretrizes e Bases da Educação (BRASIL, 1996).

\footnotetext{
${ }^{1}$ Resultados parciais do Clique do sagrado já foram publicados nos anais do VIII Seminário Nacional- Religião e Sociedade: O Espaço do Sagrado no Século XXI, NUPPER (Núcleo Paranaense de Pesquisa em Religião), de novembro de 2015; comunicação no Fórum de boas práticas do PUCPR em 2015 e artigo na Revista Paralellus (JUNQUEIRA; RODRIGUES, 2017).
} 
O "Clique do Sagrado" consiste em fotografar, utilizando celular ou câmera fotográfica, uma cena do cotidiano ou espaço que remeta a uma expressão do sagrado ou a uma dimensão religiosa/espiritual. A foto deve ser autoral e atual. O objetivo é fazer uma reflexão acerca do sagrado e dos termos que envolvem o campo do sagrado, construindo um diálogo com as percepções do sagrado, que se manifesta cotidianamente, e a percepção de teóricos que se debruçaram sobre esse tema.

As amplas transformações de natureza científica, tecnológica, política, econômica, social e cultural, levam a pensar em uma formação que possibilite a leitura dos sucessivos e complexos acontecimentos do cotidiano, que de alguma forma interferem nos mais diversos aspectos, inclusive as questões existenciais. Reflete-se, assim, sobre as questões transcendentes que a complexidade e transdisciplinaridade trazem.

A leitura religiosa no espaço escolar está alicerçada nos princípios da cidadania, no entendimento do outro enquanto outro. No contexto de democracia multicultural, a existência e a importância das múltiplas identidades culturais e religiosas são entendidas como fundamentais para a existência e a realização ética de diversos e diferentes grupos sociais.

No Clique do Sagrado, o Sagrado se tornou fonte de leitura. Imagens, símbolos, gestos e espaços são os elementos que constituem essa leitura. Para Eliade (1992), o sagrado se manifesta sempre como uma realidade inteiramente diferente das realidades naturais. As hierofanias, as manifestações do sagrado, podem ocorrer em qualquer coisa, desde em um simples objeto até em uma pessoa, e tendem a estruturar a vivência do ser humano religioso.

Uma foto e um texto curto como uma postagem em rede social era a primeira proposta da atividade. Na análise de 15 documentos de 2015, foi possível destacar as concepções de Sagrado elencadas em 2006 por Corrêa, em sua dissertação de Mestrado, ao analisar 300 questionários a professores licenciados em diferentes áreas do conhecimento que participaram de um simpósio promovido 
pela Secretaria de Educação do Paraná, no ano de 2005, no mês de julho, na cidade de Faxinal do Céu, no Centro de Capacitação Docente do Estado do Paraná. A autora chega aos seguintes indicadores: sagrado ligado à cultura, à religião, à transcendência, aos valores (humanos e sociais) e ao sentimento (CORRÊA, 2006).

A partir dessa pesquisa, foi possível identificar, nos 15 "cliques" no Blog "Um clique do Sagrado", de 2015:

- 5 atividades com elementos da natureza como céu, sol, luz, lagarta e borboleta (concepção do sagrado ligada à transcendência);

- 4 atividades com símbolos ou espaços sagrados (concepção do sagrado ligada à religião);

- 1 atividade com uma representação agnóstica e outra com imagem de um jogo digital (concepção do sagrado ligada à cultura);

-3 atividades com objetos como chaveiro, relicário e carro (concepção do sagrado ligado ao sentimento);

- 1 atividade com selfie para representar a vida, pois estava grávida (concepção do Sagrado ligada aos valores).

Os documentos analisados representam a diversidade cultural e religiosa presente em sala de aula e revelaram uma atitude de abertura às diferentes manifestações religiosas ou a ausência delas.

A Estudante A (2015) fotografou uma borboleta e em seu texto expressa: "O sagrado pode ser encontrado de várias formas, principalmente na natureza. A borboleta, com sua beleza e complexidade, nos mostra como uma pequena criatura carrega um pouco de mistério e perfeição" (Fonte: Blog Clique do Sagrado, 2015). 
De acordo com Ribeiro, é preciso observar as vivências religiosas a partir de uma lógica plural conectada às demais experiências humanas, religiosas ou não, e "como se inter-relacionam e se interpelam e como podem expressar seus valores fundamentais, mais compreensíveis serão as linguagens da religião" (2012, p. 212).

A Estudante B (2015), por exemplo, relata seu processo de reflexão sobre o Sagrado: "O sagrado para mim é representado de forma abstrata. Podemos nos sentir em contato com o Divino nas mais diversas situações, desde uma conversa, uma reflexão, um vento tocando seu rosto, uma tarde de sol, um abraço, um beijo, um olhar até um momento de silêncio" (Fonte: Blog Clique do Sagrado, 2015).

A Estudante B (2015) traduz seu sentimento para ações (conversar, refletir, ficar em silêncio...), expressa sua crença e valores, e simboliza o que só pode ser experimentado. Para Sommerman, Santos, Santos e Yukizaki (2009, p. 119), "a transcendência humana ainda é um aspecto não abrangido pela ciência. O ser humano é um ser ambíguo e crísico (de crise) que para seu equilíbrio necessita do sentimento de estar conectado a uma visão do todo". Para os autores, perante incertezas da vida, o ser humano busca "modelos de estruturação do pensamento que lhe permitam explicar a existência, surgindo os modelos mitológico-religioso, filosófico, teológico e científico". E nesse aspecto, a diversidade religiosa, a partir do conhecimento religioso no viés da transdisciplinaridade, compõe esse processo de leitura.

Não há como negar a acessibilidade aos recursos tecnológicos e a utilização dos mesmos no meio educacional vêm se expandindo e o acesso à internet proporciona um ambiente interativo, colaborativo e descentralizado, trazendo formas inéditas e criativas nas dinâmicas sociais.

É a cibercultura, que pode ser "entendida não apenas como questão tecnológica, mas como atitude da sociedade contemporânea, capaz de gerar impactos socioculturais ainda poucos estudados [...]" (TEIXEIRA; CARMO JR., 2013, p. 7). Para os autores, em telefones celulares, terminais bancários, telas de computador, redes de segurança, tablets ou outros suportes, "a linguagem 
multissensorial dos novos meios passa a modelar e intermediar relações em que o corpo do homem se dobra aos efeitos encantos e tentações da máquina” (TEIXEIRA; CARMO JR., 2013, p. 7).

A proposta do "Clique do Sagrado" procura colaborar para a sistematização do conhecimento apresentado em sala de aula para uma leitura social das manifestações religiosas integrando o cotidiano e as tecnologias educacionais da ação docente.

E, nesse sentido, alguns aspectos importantes precisam ser considerados:

- o contexto social dos educandos (seus conhecimentos prévios - bagagem cultural e religiosa);

- o papel das tradições religiosas na estruturação e manutenção das diferentes culturas e manifestações socioculturais;

- a complexidade dos assuntos religiosos em função da diversidade cultural e religiosa.

O Estudante C (2015) fotografou a cena de um game e apresentou o seguinte texto:

A religiosidade está presente na vida de todos, de um jeito ou de outro. A imagem é um exemplo disso, mostrando como a religiosidade toma as formas de todo tipo de arte, como música, pinturas, estatuas, ou no caso, ela pode ser representada dentro de um jogo digital. A imagem em questão foi tirada do jogo The Elder Scrolls 5: Skyrim, mostra um sacerdote de um dos deuses do universo do jogo falando para uma praça de seu deus. No contexto, existe também uma representação de conflito entre religiões, onde a crença do povo local começa a se misturar com outras crenças vindo de outras partes do mundo do jogo (Fonte: Blog Clique do Sagrado, 2015).

A leitura do Sagrado é a leitura do cotidiano e, nesse contexto, então, é proposto o exercício de não somente ler o religioso, mas educar para "saber olhar" o ser humano em sua diversidade de manifestações. 
A foto da Estudante D (2015) é uma mandala de fitas e em seu texto percebese que a estudante consegue expressar, princípios cujas fontes não advêm do universo religioso.

Sou agnóstica, e este é meu click, está na parede da minha casa, meus desejos e de minhas colegas para 2015. [...]. Baseio meus valores de vida no Humanismo, Secularismo e Racionalismo. Explicando brevemente, o Humanismo é uma postura de vida democrática e ética, que afirma que os seres humanos têm o direito e a responsabilidade de dar sentido e forma às suas próprias vidas. Defende a construção de uma sociedade mais humana, através de uma ética baseada em valores humanos e outros valores naturais, dentro do espírito da razão e do livre-pensamento, com base nas capacidades humanas [...] (Fonte: Blog Clique do Sagrado, 2015).

O convívio com o diferente possibilita o vislumbre do espaço da religião, das representações, das expressões e percepções do pensamento religioso e das filosofias de vida como fonte de aprendizagem.

Candau assume uma perspectiva intercultural que visa promover uma educação para o reconhecimento do “outro”, para o diálogo entre os diferentes grupos sociais e culturais. "A perspectiva intercultural está orientada à construção de uma sociedade democrática, plural, humana, que articule políticas de igualdade com políticas de identidade.” (CANDAU, 2008, p. 52).

Outro fator que a autora destaca é que não deve "desvincular as questões da diferença e da desigualdade presentes hoje de modo particularmente conflitivo, tanto no plano mundial quanto de diferentes sociedades.” (CANDAU, 2014, p. 29).

Nos “cliques" produzidos pelos/as estudantes percebe-se uma atitude de abertura às diferentes manifestações religiosas ou a ausência delas. Em meio a conteúdos formais, os recursos didáticos com base em abordagens artísticas das expressões religiosas como música, dança, pintura, escultura, teatro, literatura, cinema, fotografia e arte digital possibilita a superação de preconceito em relação ao sagrado e à religião na sociedade e abre espaço para o diálogo com o diverso, trazendo ao debate os problemas da sociedade atual como, por exemplo, a valorização de diferentes grupos sociais, políticos, econômicos, étnicos, religiosos 
etc., possibilitando a reflexão de questões que contemplem as diferenças, ou seja, a diversidade na e da sociedade que compõe o espaço universitário.

\section{Sagrado: uma dimensão cultural contextualizada}

Em 2018, outras metodologias ativas foram incorporadas à atividade. $\mathrm{O}$ estudante deveria produzir um storytelling, uma história sobre a foto. É a narrativa com recurso visual. Na atividade proposta, os estudantes desenvolvem uma história a partir de um conteúdo acadêmico, o Sagrado. Agora a contextualização e a significação do objeto deveriam ser mais exploradas e especificadas em pelos menos 35 linhas.

As histórias existem em todos os tempos, lugares e sociedades. A contação de história é uma retomada do passado na contemporaneidade, por meio de linguagens tradicionais e atuais. A história é entendida no "Clique do Sagrado" não como no passado, com pessoas sentadas ao redor de uma fogueira, ouvindo aquele sujeito detentor do conhecimento, geralmente o mais velho de uma tribo ou sociedade, que passaria adiante culturas, tradições e valores de seu povo. Ela é uma comunicação aberta à transformação.

Para Xavier (2015, 15), o storytelling é retomado no mundo digital, “trazendo novas conexões, novas oportunidades de expressão, novos poderes, novas incertezas: uma realidade em que todos se tornam geradores de conteúdo e unidades de mídia ao mesmo tempo”.

Toda narrativa possui uma estrutura que conduz e organiza os fatos. Essa construção é o que dá sentido àquilo que se quer contar. Por isso, é preciso saber combinar vários fatores para estruturar bem uma história. Entre esses fatores estão a organização da sequência dos eventos (cronologicamente ou não), descrição de lugares, pessoas e reações, por exemplo. Ao contar sua história o estudante é o protagonista, pois é o seu ponto de vista que "determina a sequencialidade das ações narradas em que o narrador seleciona da vida o que ele deseja narrar" 
(DOMINGOS, 2009, p.8). Para o autor, "um storytelling é fazer um mergulho profundo na problemática existencial humana”.

Os documentos analisados em 2018 têm duas fontes: o Ambiente Virtual da PUCPR, que não é aberto para público externo, mas os estudantes da mesma sala podem acessá-lo; e os depoimentos sobre a atividade proposta tomados para a avaliação docente, sendo a participação espontânea dos estudantes. A estudante $\mathrm{E}$ (figura 1) fotografou uma flor que nascia entre as pedras. De forma sensível e metafórica ela descreve um fato marcante de sua vida em seu storytelling. Em um trecho de sua narrativa percebe-se a relação do Sagrado a um momento de fragilidade, mas como possibilidade de superação.

Portanto, o meu sagrado, é perceber que eu sou muito além do que apenas uma flor sem pétalas e sim uma planta com vários ramos, vários galhos, vários brotos, e várias outras flores, com capacidade de me regenerar, com sua beleza peculiar para exibir e com seu perfume para exalar. (grifo da pesquisadora). (Fonte: Blog do Ambiente Virtual da PUCPR, 2018).

Figura 1: “Clique do Sagrado” Estudante E (2018).

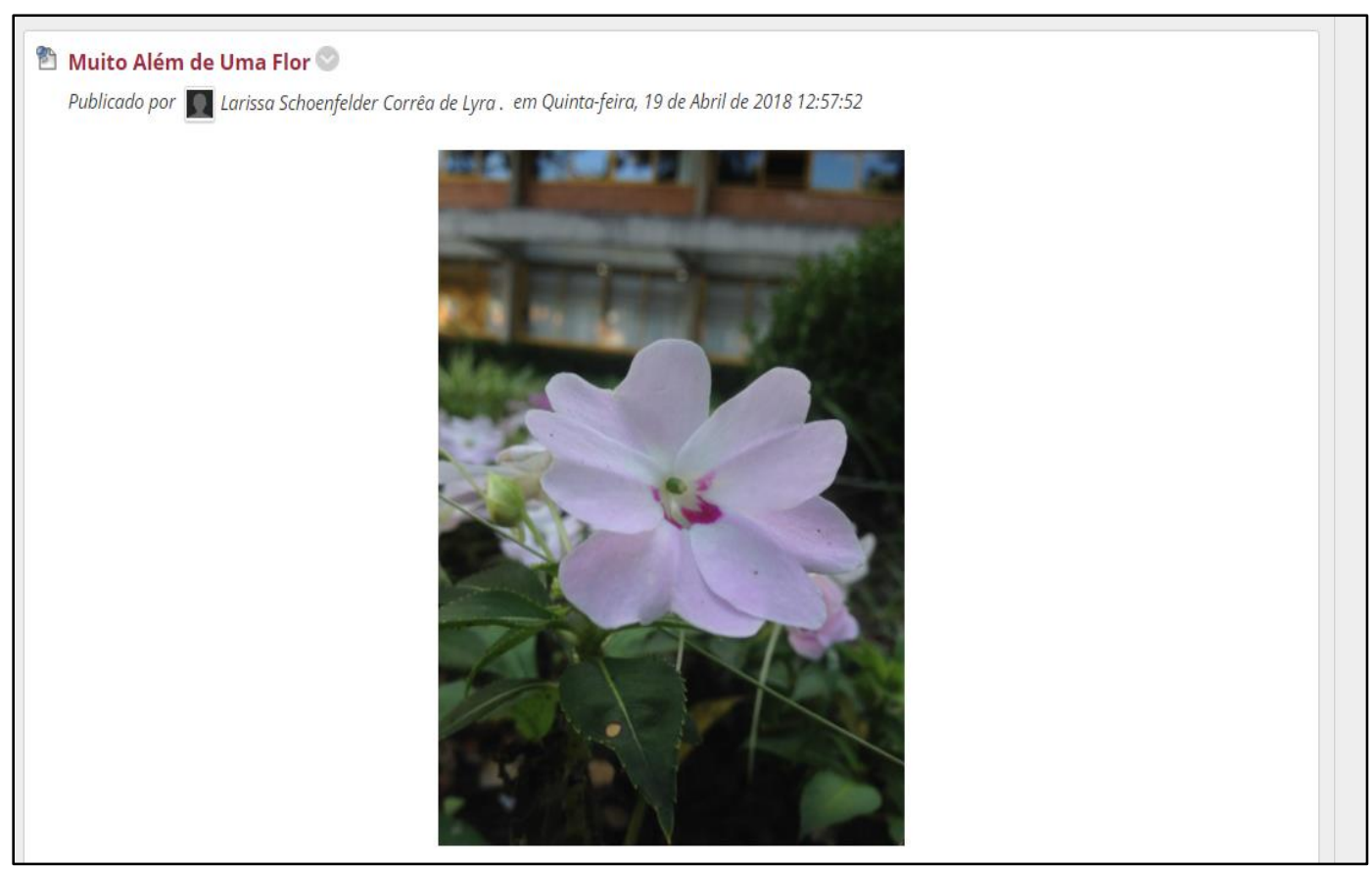

Fonte: Dados da autora. 
Percebe-se que a estudante não apenas registrou fotograficamente o sagrado ou contou uma história sobre ele. Pensando em como retratar o que considera abstrato, os estudantes traduziram seus sentimentos em retratos que expressam sua crença ou não crença, seus valores e simbolizam o que só pode ser experimentado. Pretende-se que o estudante participe ativamente da construção do processo da aquisição de seus conhecimentos, utilizando a dimensão racional de seu ser, e as dimensões sensíveis, emocionais e intuitivas. É cidadão de um mundo complexo, onde se inscrevem relações em rede, não menos complexas. Porém, é um ser dotado de capacidades criativas e talentosas, autônomo em seu processo de aprender.

Outra proposta pedagógica incorporada à atividade foi a Avaliação por Pares, uma avaliação cooperativa. Cada estudante avaliou três "cliques" com base em um checklist disponibilizado pela professora. Além disso, deveriam fazer uma comentário sobre o "clique" do colega e apontar se o mesmo atendia ao checklist proposto como: autoria da foto, número mínimo de linhas, referência aos conceitos apresentados em texto e em aula e a devida revisão ortográfica. Essa avaliação permite ao estudante cujo "clique" está sendo lido reorganizar sua atividade a partir do comentário dos colegas e assim fazer a entrega definitiva do trabalho com mais segurança.

A mesma estudante do "clique" anterior (Estudante E - 2018) apresenta o seguinte comentário sobre o clique de sua colega:

(nome da estudante avaliada) fala sobre o poder, significado das palavras, destacando a palavra "fé" em seu texto. O texto me trouxe uma grande reflexão, [...]. Por fim me fiz uma pergunta, me aproximando de seu texto: quando deixaremos nossas palavras simplesmente voarem ao vento? (Estudante B, 2018). (Fonte: Blog do Ambiente Virtual da PUCPR, 2018).

Teixeira (2012) aponta os desafios fundamentais que se apresentam ao século XXI e destaca a acolhida da diversidade religiosa como um imperativo dialogal. Ele apresenta a diferença religiosa como enigma - misteriosos caminhos 
que levam os seres humanos a buscar um novo entendimento e compreensão em sua trajetória de vida.

A diversidade religiosa advinda da elaboração cultural, sempre esteve presente na história da humanidade, como uma forma de questionar sobre o sentido da vida e da transcendência. E de acordo com Corrêa (2008, p. 149), como uma das características mais marcantes do povo brasileiro, a religiosidade "se manifesta de múltiplas maneiras como decorrência de um lado das diferentes religiões praticadas na sociedade brasileira e, de outro, como parte do modo de ser de muitos indivíduos ainda que não professem uma religião em especial". Dentro dessa perspectiva, cada religião assume diferentes formas de acreditar, de celebrar, de rezar, e de relacionar-se com outro e de simbolizar de formas diferentes as experiências religiosas vivenciadas pelo povo de cada cultura religiosa.

Após a Avaliação por Pares, foi proposto aos estudantes a autoavaliação. A autoavaliação da Estudante E (2018) aponta o processo reflexivo na execução da atividade.

Uma das maiores dificuldades durante o Clique do Sagrado foi, sem dúvida alguma, me abrir. Foi um momento que me deixei ser vulnerável, que me trouxe dor, lágrimas, mas acima de tudo, me trouxe reflexão. Uma reflexão que eu vinha procrastinando em fazer, pois não sabia como o Clique do Sagrado foi uma oportunidade e foi assim que eu o encarei desde o início. Foi uma chance de me abrir principalmente comigo mesma, que me tornou diferente do início do semestre. Foi um trabalho pelo qual eu só consigo sentir uma coisa: GRATIDÃO. (Fonte: Blog do Ambiente Virtual da PUCPR, 2018).

Todo ser humano vive e se desenvolve no interior de um conjunto muito complexo de relações, intercâmbios, colaborações e rivalidades. E os laços de linguagem, de cultura e de amizade configuram o surgimento e o desenvolvimento de cada pessoa singular. A partir desses laços, cada um é estimulado e limitado pelos outros seres humanos, e há uma singularidade pessoal na relação com o outro, que pensa e crê diferente. Para a Estudante F (2018), 
às vezes não percebemos o quão precioso é aquilo presente em nosso cotidiano. A atividade "Clique do Sagrado" possibilitou que a minha visão se tornasse mais clara sobre aquilo que é de fato importante para mim, além de conhecer o que importa na vida dos meus colegas. Foi uma atividade que se expandiu para além dos limites da faculdade e que vou com certeza levara para a vida. (Fonte: Blog do Ambiente Virtual da PUCPR, 2018).

Os/as estudantes olham para si, olham para os outros e tornam a olhar para si, mas agora se apropriando do olhar do outro, desenvolvendo respeito e solidariedade.

Pensar o outro disponível para uma nova interlocução criadora, segundo Teixeira (2012, p.181), pode provocar uma ampliação de olhar e enriquecimento próprio com novas possibilidades de um processo que não acontece sem disposições prévias.

O processo foi muito intenso e rico e mobilizou toda a turma. Em depoimento coletado para avaliação interna da instituição, a Estudante E (2018) relata a experiência do clique com o uso das metodologias ativas.

foi, provavelmente, o trabalho acadêmico mais importante para a minha vida, foi um importante momento de reflexão que tive que fazer sobre o que era importante na minha existência, um momento que pude me abrir e repensar vários eventos que ocorreram e, não apenas isso, toda a dinâmica de poder ler as histórias de meus colegas de classe também foi muito esclarecedor, já que pudemos nos aproximar, não apenas como turma, mas como seres humanos. Eu tenho muita gratidão de ter tido a oportunidade de fazer esse trabalho e poder perceber a beleza e o sagrado nas pequenas coisas do dia a dia em diversas perspectivas. (Fonte: Depoimento para avaliação docente da PUCPR, 2018).

As estudantes F e G (2018) também participaram desse processo:

A atividade do clique do sagrado me fez transcender de uma forma avassaladora. O processo de pôr em palavras e escolher o que é sagrado me fez tirar um peso que sabíamos que existia, é um processo de expandir o seu próprio eu e também de ter empatia por meio dos outros textos dos colegas (Estudante F. Fonte: Depoimento para avaliação docente da PUCPR, 2018). 
A experiência como clique do Sagrado foi única para mim, eu não me senti fazendo um trabalho que valia nota. Esse trabalho me fez refletir muito sobre toda a minha vida e minhas experiências. Me sinto muito grata pela professora, pela proposta, por ter me feito voltar para mim (Estudante G. Fonte: Depoimento para avaliação docente da PUCPR, 2018).

A diversidade religiosa advinda da elaboração cultural, sempre esteve presente na história da humanidade, como uma forma de questionar sobre o sentido da vida e da transcendência. E de acordo com Corrêa (2008, p. 149), como uma das características mais marcantes do povo brasileiro, a religiosidade "se manifesta de múltiplas maneiras como decorrência de um lado das diferentes religiões praticadas na sociedade brasileira e, de outro, como parte do modo de ser de muitos indivíduos ainda que não professem uma religião em especial”.

Em relação ao registro próprio e a avaliação do registro do "outro", a consequência é a fixação do conhecimento percebido, aprofundamento da observação e análise crítica. Dessa forma, favorece-se o desenvolvimento das capacidades de análise e julgamento crítico, interpretação das evidências e significados para, finalmente, alcançar a apropriação da autoexpressão, participação criativa e valorização do bem cultural.

\section{Clique do Sagrado e formação docente}

Foram apresentados dois recortes temporais (2015 e 2018) sobre o "Clique do Sagrado", pois pensar o processo de ensino e aprendizagem é pensar em situações que promovam a construção dos saberes.

O estudante não existe apenas para aprender, tão pouco o/a professor/a existe para ensinar. Esse paradigma pode, em muitos casos, fazer com que se perca a dimensão de ao ensinar também se aprende. "Por duas razões: porque é o próprio processo de ensinar que nos ensina a ensinar e porque aprendemos com aquele a quem ensinamos, não apenas porque nos preparamos para ensinar, mas também porque é o momento de revermos o nosso saber na busca do saber que o estudante faz" (FREIRE; FAUNDEZ, 1985, p. 23). 
$\mathrm{Na}$ relação entre competências e conhecimentos, há que se pensar na perspectiva metodológica, propiciando situações de aprendizagem focadas em situações-problema ou no desenvolvimento de projetos que possibilitem a interação dos diferentes conhecimentos. Essas situações de ensino e aprendizagem são situações comunicativas, nas quais eu me coloco com os/as estudantes em atitude de coparticipação. É sobre essa base que o "Clique do Sagrado" parte como proposta pedagógica.

A reflexão pedagógica sobre um ser humano dotado de razão, afetividade, inteligência, corpo e desejo possibilita a criação de um espaço educativo aberto para o diverso, pois há pensamentos, desejos, crenças e sentimentos diversos, pois cada ser humano é único na sua diversidade.

Camas e Brito (2017, p. 316) apontam que a "relação entre ensino e aprendizagem e os tipos de metodologia utilizados em sala de aula, fazendo-se necessária a verificação da eficácia e eficiência das práticas docentes nesses processos" é uma das principais questões relacionadas à atuação docente.

O processo de ensino e aprendizagem é voltado para o desenvolvimento da capacidade de aprender a aprender e de ler a vida. A interação por meio do diálogo, em um processo dinâmico marcado pelo respeito. Nessa composição encontram-se os valores que pautam a vida da pessoa, inclusive trazendo-lhe bem-estar a partir da relação que se estabelece entre valorizada, percebe-se uma sociedade que privilegia.

Para Tardif e Lessard (2005, p. 41), o interesse das pesquisas em educação tem sido o planejamento de ensino, a avaliação da aprendizagem e do ensino, as crenças e representações de professores e professoras, os processos cognitivos e decisórios que orientam a ação prática, a produção de seus saberes, suas condições de trabalho, o envelhecimento e o desgaste profissional. Todos os dados levantados compõem uma "sólida base de conhecimentos para estudar a docência no âmbito escolar.” (TARDIF; LESSARD, 2005, p. 8). 
Muitas vezes, no âmbito educacional, associa-se a formação a um sucesso esperado para os problemas educacionais como se por encantamento ou por algo mágico pudesse ser realizado e/ou vinculado ao professor e à professora. Entretanto, professor/a e estudantes são os atores sociais que ocupam o espaço escolar e que compõem o ato pedagógico. Mas não só isso. Para os autores, “cultura é o conteúdo da educação, sua essência e sua defesa, e o currículo é a opção realizada dentro dessa cultura [...] por trás das nossas diferenças há a mesma humanidade”. (RODRIGUES; JUNQUEIRA; MARTINS FILHO, 2015, p. 117).

Referir-se à educação não é referir-se à instrução ou simples transmissão de conhecimentos, mas a um processo de personalização e de aquisição de meios para uma ação transformadora. É preciso ter em mente que toda prática educativa requer a existência de atores sociais, um que, ensinando aprende, outro que, aprendendo, ensina. Enquanto ensina, o educador continua buscando. Busca porque indaga e continua indagando. Ao indagar faz constatações, intervenções que resultam na própria educação e na do estudante.

A formação de professores é importante, pois o Ensino Religioso/Cultura Religiosa, como disciplina escolar, oferece uma abertura ao sentido fundamental da existência do ser humano, contribuindo na formação do cidadão, que, vivendo em sociedade, valoriza a diversidade cultural e religiosa e que sabe dialogar nela e com ela.

O educador é fundamental na consciência do aprisionamento mental ao qual o fechamento num único paradigma pode nos levar. Seu papel, hoje, é o de, ao mesmo tempo, em que provê as diretrizes humanas, libertar a consciência. Mostrar a possibilidade de um diálogo mais amplo entre os paradigmas, entre as culturas, entre os valores, entre os saberes, entre as disciplinas, e também entre os diferentes níveis de realidade e os diferentes níveis de percepção do ser humano, em busca de uma humanidade mais plena, profunda, ética e solidária. (SANTOS; SANTOS, 2009, p. 124).

Quando o estudante universitário ou do ensino fundamental é instigado a perceber o "outro", porque essa percepção já foi apropriada pelo professor, a universidade/escola torna-se o espaço para o diálogo, a humanização das relações e da educação para a liberdade e o respeito das diferenças culturais e religiosas. 


\section{Considerações finais}

Na disciplina de Cultura Religiosa, pretende-se que o/a estudante participe ativamente da construção do processo da aquisição de seus conhecimentos, utilizando a dimensão racional de seu ser, e as dimensões sensíveis, emocionais e intuitivas.

Contudo, o fazer pedagógico não se revela apenas nas intenções definidas em ementas ou currículos, mas particularmente no cotidiano escolar/universitário, para congregar os discursos científico, político, estético e religioso no mesmo campo cognitivo.

Não foi objetivo desta pesquisa conceituar o Sagrado, pois apesar do título da atividade, parte-se da premissa de ajudar o estudante a perceber a diversidade cultural e religiosa, expressa na dimensão do Sagrado.

Para que os/as estudantes discutam e opinem sobre suas inquietações e aspirações pessoais e coletivas é preciso criar espaços para tais discussões. Segundo Passos, não há distância ou oposição entre o conhecimento religioso e conhecimento racional e afirma que o conhecimento religioso é "composto como negociação complexa entre indivíduos e disposto em uma temporalidade capaz de amadurecer e produzir consensos” (PASSOS, 2011, p. 79), compondo uma visão de realidade.

A atividade Clique do sagrado propõe uma leitura no cenário local, colabora para fomentar o diálogo inter-religioso e a tolerância a toda e qualquer religião, procurando formar cidadãos abertos para a diversidade cultural e religiosa. Os documentos do "Clique do Sagrado" analisados revelam uma atitude de abertura a diferentes manifestações religiosas, ou a ausência delas, possibilitando a superação do preconceito em relação ao Sagrado e à religião na sociedade e abre espaço para o diálogo com o diverso, trazendo ao debate os problemas da sociedade atual como, por exemplo, a valorização de diferentes grupos sociais, políticos, econômicos, étnicos e religiosos possibilitando a reflexão de questões que contemplem as 
diferenças, ou seja, a diversidade na e da sociedade que compõem o espaço universitário.

A atividade vem se desenvolvendo desde 2015 e a partir dos estudos até aqui desenvolvidos, pode-se verificar algumas condições de aprendizagem para a compreensão do conhecimento religioso e a diversidade em sala de aula, que aqui se retomam, considerando as metodologias ativas:

1. Desenvolver experiências de aprendizagem a partir de um re-olhar dos bens culturais e religiosos do próprio ser humano;

2. Produzir conhecimento pertinente a partir desses bens culturais e religiosos;

3. Relacionar as releituras ao contexto dos estudantes para a percepção de si e do outro;

4. Promover a tomada de consciência de que esse olhar para o sagrado é a minúscula parte de um conjunto muito mais amplo que permite o conhecimento do passado, do mundo e do Outro.

É sobre essa base que o Clique do Sagrado parte como proposta pedagógica. A expansão dos saberes em torno do sagrado amplia o conhecimento religioso, que constitui patrimônio da humanidade. E em relação ao uso das metodologias ativas, o re-olhar (para dentro, para fora e para o outro) e a contextualização são atitudes essenciais para a prática docente.

A atividade já se repetiu por mais cinco semestres, com turmas diferentes e demais professores da disciplina, que adotaram a atividade em suas propostas de ensino, inclusive variando a temática como por exemplo, xenofobia e intolerância religiosa e responsabilidade com a casa comum (tema da Campanha da Fraternidade de 2017). 
Pode-se afirmar que o "Clique do Sagrado" contribuiu para a leitura do sagrado no cotidiano. É fato, porém, que muitas tentativas, entre erros e acertos, foram necessárias para sistematizar o processo de maneira a garantir uma leitura que supere a superfície das coisas, acontecimentos, gestos, ritos, normas e formulações, para a compreensão da realidade de maneira profunda, favorecendo a reflexão sobre aspectos fundamentais da existência humana e do Sagrado, para promover a inserção do/a estudante nas questões do dia a dia, nas quais essas reflexões não podem estar ausentes.

Conhecer o humano e aprender a "olhá-lo" na sua especificidade é, antes de mais nada, situá-lo no universo e não separá-lo dele. O pressuposto é que os estudantes têm o direito de conhecer todas as dimensões da cultura; entre essas, encontra-se a possibilidade de discutir os problemas fundamentais da existência. É difícil chegar às opções de vida, quando se pretende ignorar a religião que tem tanto a dizer, ou então, quando se quer restringi-la a um ensino vago, inútil, por ser destituído da relação entre os modelos históricos, coerentes com a tradição e a cultura dos povos.

O convívio com o diferente como fonte de aprendizagem, pelo viés da interculturalidade, é a premissa dessa atividade, pois se entende que é pela ação do ser humano que vislumbra o espaço da religião, as representações, as expressões e percepções do discurso religioso e do pensamento religioso que o diálogo se estabelece. O desafio, portanto, é promover o diálogo considerando a comunicação, a subjetividade, as reflexões, as ações, as observações, as impressões, as irritações, os sentimentos e a fé. Por meio do diálogo, em um processo dinâmico marcado pelo respeito, é possível reconhecer o conhecimento produzido por diferentes tradições religiosas ou filosofias de vida.

Em meio a conteúdos formais, o "Clique do Sagrado" é uma proposta para a superação de preconceito em relação ao sagrado e à religião na sociedade. Abre espaço para o diálogo com o diverso, possibilitando a reflexão de questões que contemplem as diferenças, ou seja, a diversidade na e da sociedade que compõe o espaço universitário. Traz ao debate os problemas da sociedade atual como, por 
exemplo, a valorização de diferentes grupos sociais, políticos, econômicos, étnicos e religiosos.

O/a estudante participa ativamente da construção do processo da aquisição de seus conhecimentos, utilizando a dimensão racional de seu ser, e as dimensões sensíveis, emocionais e intuitivas. É cidadão/ã de um mundo complexo, onde se inscrevem relações em rede, não menos complexas, pois a expansão dos saberes em torno do sagrado amplia o conhecimento religioso e contribui para o desenvolvimento de cidadãos com postura crítica diante de problemas sociais e engajamento na sua resolução.

\section{REFERÊNCIAS}

BRASIL. Lei de diretrizes e bases da educação nacional LEI 9394/96. Brasília: MEC, 1996.

CAMAS, Nuria Pons Vilardell; BRITO Glaucia da Silva. Metodologias ativas: uma discussão acerca das possibilidades práticas na educação continuada de professores do ensino superior. Revista Diálogo Educacional, Curitiba, v. 17, n. 52, p. 311-336, abr./jun. 2017.

CANDAU, Vera Maria. Direitos humanos, educação e interculturalidade: as tensões entre igualdade e diferença. Revista Brasileira de Educação, v. 13, n. 37, jan./abr. 2008.

CANDAU, Vera Maria. Educação intercultural: entre afirmações e desafios. In: MOREIRA, A. F.; CANDAU, V. M. (org.). Currículos, disciplinas e culturas. Petrópolis: Vozes, 2014 .

CORRÊA, Bárbara Raquel do Prado Gimenez. Concepções dos professores sobre o sagrado: implicações para a formação docente. Dissertação de Mestrado em Educação. Pontifícia Universidade Católica do Paraná, Curitiba, 2006.

CORRÊA, Rosa Lydia. Teixeira. Cultura e diversidade. Curitiba: IBPEX, 2008.

DOMINGOS, Adenil Alfeu. Storytelling: evolução, novas tecnologias e mídia. Intercom Sociedade Brasileira de Estudos Interdisciplinares da Comunicação XXXII. Congresso Brasileiro de Ciências da Comunicação - Curitiba, PR - 4 a 7 de setembro de 2009.

ELIADE, Mircea. O sagrado e o profano. São Paulo: Martins Fontes, 1992. 
FIGUEIREDO, Nébia Maria Almeida. Método e metodologia na pesquisa científica. 2. ed. São Caetano do Sul: Yendis Editora, 2007.

FREIRE, Paulo; FAUNDEZ, Antonio. Por uma pedagogia da pergunta. Rio de Janeiro: Paz e Terra, 1985. Disponível em: https://docs.google.com/viewer?a=v\&pid=sites\&srcid=ZGVmYXVsdGRvbWFpbnxlZHVjY W5kb3BhcmFsaWJlcmRhZGV8Z3g6N2M5MTBkMDQ2NzVjMTQ3Yg. Acesso em: 2 out. 2019.

JUNQUEIRA, Sérgio Rogério Azevedo; RODRIGUES, Edile Maria Fracaro. Diversidade no Sagrado: em cliques. Paralellus, Recife, v. 8, n. 18, p. 341-358, mai./ago. 2017. Disponível em: http://www.unicap.br/ojs/index.php/paralellus/article/view/1015. Acesso em: 12 mar. de 2019.

KLERING, José Romaldo. A disciplina de Cultura Religiosa como espaço integralizador da educação, na universidade. Teocomunicação, Porto Alegre, v. 41, n. 1, p. 128-149, jan./jun. 2011.

MORIN, Edgar. A cabeça bem-feita. Rio de Janeiro: Bertrand Brasil, 20oob.

MORIN, Edgar. Os sete saberes necessários à educação do futuro. São Paulo: Cortez, 2000a.

MORIN, Edgar. Planetarización y crisis de la humanidade. Educación: revista de educación moderna para una sociedad democrática, México, n. 152, enero 2008.

PASSOS, João Décio. Teologia e outros saberes: uma introdução ao pensamento teológico. 2. ed. São Paulo: Paulinas, 2011.

RODRIGUES, Edile Maria Fracaro. "Retratos” da diversidade cultural e religiosa contribuições para uma formação de professores de ensino religioso. Tese (Doutorado em Teologia), Pontifícia Universidade Católica do Paraná - PUCPR, Curitiba, 2018.

RODRIGUES, Edile Maria Fracaro. Desenvolvimento religioso. In: JUNQUEIRA, Sérgio, BRANDENBURG, Laude, KLEIN, Remi. Compêndio do Ensino Religioso. São Leopoldo: Sinodal; Petrópolis: Vozes, 2017. p. 207-2015.

RODRIGUES, Edile Maria Fracaro. Em riscos e rabiscos: concepções de ensino religioso dos docentes do ensino fundamental do estado do Paraná - possibilidades para uma formação de professores. Dissertação (Mestrado em Educação), Pontifícia Universidade Católica do Paraná - PUCPR, Curitiba, 2008.

RODRIGUES, Edile Maria Fracaro. Vote na sua foto preferida. Blog "Um clique do sagrado" Disponível em: http://umcliquedosagrado.blogspot.com.br. Acesso em: 2 out. 2019.

RODRIGUES, Edile Maria Fracaro; JUNQUEIRA, Sérgio Rogério Azevedo; MARTINS FILHO, Lourival José. Perspectivas pedagógicas do ensino religioso: formação inicial para um profissional do ensino religioso. Florianópolis: Insular, 2015. 
SANTOS NETO, José Martins dos. Cultura religiosa e inserção acadêmica. Horizonte, Belo Horizonte, v. 2, n. 4, p. 145-148, $1^{\circ}$ sem. 2004. Disponível em:

http://seer.pucminas.br/index.php/horizonte/article/view/590/617. Acesso em: 2 out. 2019.

SANTOS, Ana Cristina Souza; SANTOS, Akiko. Obstáculos epistemológicos no diálogo dos sabres. In: SANTOS, Akiko; SOMMERMAN, Américo (org.). Complexidade e

transdiciplinaridade: em busca da totalidade perdida. Porto Alegre: Sulina, 2009.

SOMMERMAN, Américo; SANTOS, Ana Cristina Souza; SANTOS, Akiko; YUKIZAKI, Suemy. O que há entre teoria e prática. In: SANTOS, Akiko; SOMMERMAN, Américo (org.). Complexidade e transdiciplinaridade: em busca da totalidade perdida. Porto Alegre: Sulina, 2009. p. 99-127.

TARDIF, Maurice; LESSARD, Claude. O trabalho docente: elementos para uma teoria da docência como profissão de interações humanas. Petrópolis: Vozes, 2005.

TEIXEIRA, Faustino. O imprescindível desafio da diferença religiosa. Revista Interdisciplinar da Mobilidade Humana, Brasília, v. XX, n. 38, p. 181-194, jan./jun. 2012.

TEIXEIRA, Lucia; CARMO JR., José Roberto do (org.). Linguagens na cibercultura. São Paulo: Estação das Letras e Cores, 2013.

XAVIER, Adilson. Storytelling: histórias que deixam marcas. Rio de Janeiro: Best Business, 2015. 